\title{
Iluminismo aristocrático no período de Humano, demasiado Humano
}

Aristocratic Enlightenment in the Human, all too human Period

Ivo da Silva Júnior

Universidade Federal de São Paulo

\section{RESUMO}

Esse trabalho tem como objetivo investigar as razões pelas quais Nietzsche passa a advogar posições de caráter nitidamente iluminista no período intermediário de sua obra. Para tanto, examina o papel da guerra franco-prussiana e seus desdobramentos no deslocamento conceitual operado na obra do filósofo.

\section{PALAVRAS-CHAVE}

Iluminismo; Aristocracia; Modernidade; Nacionalismo; Guerra franco-prussiana.

\begin{abstract}
This paper aims at investigating the reasons why Nietzsche advocates positions of the Enlightenment Philosophy in the middle period of his work. For this purpose, it examines the role of the Franco-Prussian war and its consequences for the conceptual framework in philosophers thought.
\end{abstract}

\section{KEY WORDS}

Enlightenment; Aristocracy;

Modernity; Nationalism;

Franco-Prussian War. 
Os pensadores anti-iluministas nunca foram conservadores, mas revolucionários de uma nova espécie.

Salta aos olhos que a filosofia de Nietzsche coloca-se como antípoda a qualquer rasgo de cunho iluminista, sobretudo quando consideramos as obras publicadas a partir de Assim falava Zaratustra. Outrossim, algo não muito diferente ocorre quando analisamos os textos de juventude do filósofo. No entanto, no período de Humano, demasiado Humano, fica igualmente claro um influxo nas posições filosóficas de Nietzsche, que marcadamente tende para as Luzes. Longe de considerarmos esse período intermediário um ponto fora da curva, visamos aqui a esboçar os elementos que nos permitirá afirmar a perfeita consonância das posições do filósofo com os outros momentos da sua obra, por conta, sobretudo, da constância de um dos seus alvos principais de ataque, qual seja, a crítica à modernidade. ${ }^{2}$

A vitória alemã na batalha de Sedan, em setembro 1870, muito entusiasma Nietzsche. A derrota fragorosa da França, que pôs fim ao Segundo Império, e contribuiu para a instauração da Terceira República, provocaria ao mesmo tempo, no ver do filósofo, a derrocada dos ideais iluministas que surgiram com a Revolução Francesa, atingindo com isso o liberalismo e a democracia então em voga em diversas nações europeias. É nesse contexto que se inserem as reflexões de Nietzsche no Nascimento da Tragédia, em que o otimismo socrático teria sido atingido de morte, afastando, por conseguinte, um otimismo iluminista de cunho eminentemente francês e trazendo a expectativa de uma Alemanha que viesse a encarnar a tarefa trágica e helênica de renovação da cultura (Bildung).

No entanto, a vitória alemã, sob os auspícios da Prússia, não segue o trajeto aguardado por Nietzsche. Dada a oposição cultural entre alemães e franceses (a chamada cultura alemã, de um lado, e a civilização francesa, de outro), o filósofo esperava que ocorresse a preservação e o aprofundamento da concepção alemã de cultura num viés aristocrático. Expectativa essa que foi solenemente frustrada uma vez a "via prussiana" (na expressão leniniana) aberta, verdadeiro rolo compressor do avanço econômico capitalista, que altera toto coelo a face política e social alemã.

Muito rapidamente, Nietzsche começa a se inquietar pelos novos rumos

I Sternhell, 2006, p. 27I.

2 Esse trabalho é uma versão que tem por base o texto "As posições políticas de Nietzsche em Humano, demasiado Humano: um pensador das Luzes?" (Silva Jr., 20I7). Apoia-se ainda, na linha de outros que temos realizado, em muitas análises e considerações desenvolvidas por Losurdo, 2009. 
da nova nação, em particular pelo empenho do II Reich na promoção de uma educação para uma massa até então não contemplada pelo ensino. $\mathrm{O}$ texto das conferências Sobre o Futuro de nossos Estabelecimentos de Ensino, de 1872, aborda essa questão. O liceu que era o locus onde poderia vicejar um homem antimoderno e antidemocrático, doravante parece ter sido rifado pelas novas prioridades apregoadas pelo Reich. Se, de um lado, o novo Reich precisa se legitimar (e para isso a filosofia de Hegel cai como uma luva), de outro, para se manter, tem de apostar na saída do pré-capitalismo. E, para tanto, reformular o liceu, dando a ele outra dimensão e outro caráter, é fundamental.

Nietzsche não deixa então de expressar claramente a necessidade de uma formação voltada contra as diretrizes educacionais de sua época, que vise unicamente à formação de alguns poucos. Se para o embate com o mundo moderno o filósofo coloca todas as suas fichas na educação, com propostas concretas, isso não se faz sem um estrito senso de realidade. Sabe que esse é o ponto fulcral nesse momento.

Distante da renovação cultural então vislumbrada, diante, no entanto, da derrota de uma genuína alma e cultura alemãs para a Realpolitik, Nietzsche se depara com a difusão da instrução, com um verdadeiro iluminismo de massa para as camadas urbanas (e para os soldados inclusive), enfim com uma nova face do mundo, que impossibilita doravante o surgimento de grandes indivíduos a favor de uma multidão esclarecida guiada pelo Estado. Em suma, se num mesmo momento Nietzsche se mostra esperançoso com a possibilidade de os alemães aprofundarem a via que lhes é natural (com a publicação de $O$ Nascimento da Tragédia), mostra-se também muito reticente (com as conferências Sobre o Futuro). Apenas após longa maturação, que ocorre no período de Humano, demasiado Humano, dá-se por convencido de que um movimento contranatural venceu juntamente com a vitória alemã na guerra franco-prussiana.

Para além dos desdobramentos culturais com o declínio da Bildung, Nietzsche tem outros receios: trazer as luzes para o povo pode ser um meio de criar mecanismos para revoltas contra um status quo determinado, em particular no que tange à estruturação da sociedade alemã. Vê essa sua percepção respaldada pelos movimentos de operários que começam a se construir. É a partir desse momento, em que fica claro que o programa do Nascimento da Tragédia de recuperar a antiguidade de que o povo alemão é herdeiro fracassa, que o filósofo pode ser visto como um "revolucionário de uma outra espécie".

Nietzsche, desde a juventude, posiciona-se com firmeza contra tudo que seja da lavra do que irá denominar posteriormente de "ideias modernas". Talvez ainda mais: não apenas coloca-se contra, mas nega fortemente a modernidade, como muitos aliás em sua época, sem considerar de forma alguma um movimento dialético dos acontecimentos do mundo. Com o seu primeiro livro publicado, 
o filósofo era bem sucedido na contraposição entre o homem teórico, o otimista moderno frente a um mundo economicamente promissor, e o homem dionisíaco. Em termos práticos, no entanto, essa contraposição não resultava em algo muito distante do provocado pela "crise de Kant", que despertara outrora certo imobilismo para a ação ao colocar o home face a face ao vazio. ${ }^{3}$

A segunda e a terceira Considerações Extemporâneas trazem justamente duas figuras (Schopenhauer e Wagner) que podem ir para além dos resultados dessa contraposição, pois são, no limite, os modelos de uma educação bem sucedida; são, ao contrário dos novos formandos ou de seus formadores incrustados no Estado, homens antimodernos por excelência. Se a crítica é feita de forma abrangente às "ideias modernas" e o que elas representam; se o iluminismo é devidamente desmascarado, resta algo que precisa ser ajustado e o é nas Consideraçōes extemporâneas. Esse algo - a falta de um estímulo que ultrapasse a negação - constitutivo do quadro conceitual do Nascimento da Tragédia, sai de cena e abre espaço para um motor de cunho iluminista que permite a ação ter o seu devido curso. Tudo isso forçado, repitamos, pela evidência de que o programa do Nascimento da Tragédia não teria viabilidade. Em uma palavra, os acontecimentos hodiernos ao filósofo passam a exigir um quadro conceitual de outra ordem.

É nesse momento que Nietzsche se "converte" ao iluminismo ${ }^{4}$. Isso não quer dizer que os seus alvos, a democracia (ponta do iceberg da modernidade) e os movimentos revolucionários, deixaram de fazer parte de suas preocupações. Muito pelo contrário, a mudança do quadro conceitual com que passa a operar visa a uma eficiência maior nos seus ataques. Lembremos sempre que há por trás de sua visão de mundo a sagrada Bildung dando o norte.

3 À diferença de muitos de seus contemporâneos, que sucumbiram em decorrência do niilismo trazido pela "crise de Kant", o jovem filósofo se considera muito bem educado por Schopenhauer que, no seu ver, não sucumbiu à impossibilidade de acesso ao em si e abandonou qualquer esperança que esse acesso permitiria (a realização terrena de um mundo idealizado). Pode manter então a expectativa num tipo de homem que fosse o antípoda do homem moderno, demonstrando assim uma firme disposição para o embate. A esse respeito, ver Silva Jr., 2007, pp. 33-76.

4 Nessa direção, vale a pena irmos às observações de Lebrun, que num primeiro momento anota a "influência que exerce sobre Nietzsche [...] a imagem da Cidade orgânica grega" na época do "Estado grego": "Na linhagem do helenismo piedoso de Schiller e do jovem Hegel, também Nietzsche vem celebrar, na Cidade ética, o necessário instrumento da arte, e a condição para que desabroche o gênio". E, num segundo momento, observa que, com Humano, demasiado Humano, o tom muda: "Já não se cogita da 'obra de arte estatal', nem de um Estado que possa se dedicar a produzir o gênio. Foi certo açodamento honrar a Pólis clássica como uma organização guerreira na qual a escravidão possibilitava o florescimento da cultura - uma coletividade na qual o indivíduo só teria valor na medida em que contribuísse para a entrada do gênio em cena... O contrário é que é verdadeiro. A Cidade era uma das primeiras figuras do 'rebanho'; já consagrava o sacrifício do indivíduo à totalidade" (Lebrun, I988, p. II3). 
Se diante dos novos contornos do mundo, impossíveis de serem ignorados, no qual a Alemanha suprime deliberadamente as condiçôes que permitiriam a cultura vicejar, Nietzsche se encontra com o quadro teórico sustentado nos seus primeiros escritos completamente ultrapassado pelos acontecimentos, sem nenhum respaldo na efetividade política, social ou econômica, levando o seu pensamento a um influxo incontornável, não é, no entanto, evidente a passagem das suas posições filosóficas construídas nos seus primeiros escritos para outras de caráter iluminista. Para clarear esse ponto, talvez os deslocamentos para as novas posiçōes indiquem os motivos de sua incursão conceitual pelo iluminismo.

Nietzsche sabe que o iluminismo tem um lugar à parte na Alemanha. Se o Renascimento contribuiu com a França e a Itália para sair da Idade Média em direção às Luzes, em solo alemão a Reforma teria atrasado a "aurora do iluminismo". Conforme assevera o filósofo:

A grande tarefa da Renascença não pode ser levada a cabo, impedida que foi pelo protesto do ser alemão que então havia ficado para trás (e que na Idade Média tivera sensatez bastante para renovadamente atravessar os Alpes para a sua salvação). Foi o acaso de uma constelação política excepcional que preservou Lutero e fez o protesto ganhar força: o imperador o protegeu, a fim de usar sua inovação como instrumento de pressão sobre o papa, e do mesmo modo que o papa o favoreceu em sigilo, para usar os príncipes protestantes como contrapeso ao imperador. Sem este estranho concerto de objetivos, Lutero teria sido queimado como Hus - e a aurora do Iluminismo teria surgido um pouco antes.

Nietzsche percebe que este "ser alemão", fomentado por um estreito elo entre o cristianismo e a germanofilia, precisa ser revisto, tanto que, num parágrafo de Miscelânea de Opiniōes e Sentenças, intitulado "Ser bom alemão significa "desgermanizar-se", o filósofo diz que a questão não é mais saber "o que é alemão", mas, "o que é agora alemão". Alteração sutil que revela uma mudança conceitual, qual seja, o abandono da tarefa trágica helênica, assentada em expectativas em uma ação estatal com foco na alma e na cultura alemãs, para a focalização da nova face do momento presente.

Nietzsche se afasta então de Wagner, que acaba por se colocar em conformidade com seu tempo ao pôr-se a serviço da potência militar alemã. Rompe igualmente com o movimento nacional-liberal, pois as fichas outrora postas no nacional-liberalismo, que fariam da Alemanha uma nova Grécia, foram devidamente sequestra-

5 Humano, demasiado Humano $\$ 237$, KSA 2.199-200. Tradução conforme Paulo César Souza (Nietzsche, 2000). A partir de agora, indicado com pcs.

6 Miscelânea de Opiniōes e Sentenças $\$ 323$, KSA 2.5II-2. 
das pela burguesia ascendente. Ainda mais: entende que o partido nacional-liberal passou a ter, como o partido socialista, a multidão como referência. ${ }^{7}$

Isto constatado, o filósofo passa a analisar todos os movimentos geopolíticos de Bismarck que visavam a garantir o alavancar das mudanças econômicas. A seu ver, Bismarck, "o timoneiro das paixões", tem dois alvos principais, duas paixões a colocar em relevo, que se entrelaçam: uma delas, que servirá à sua movimentação externa, é a religião; a outra, que terá uma função interna, é o chauvinismo.

Nietzsche bem percebe que os movimentos do chanceler colidem com a Kulturkampf, isto é, a luta contra o clérigo. Ponto no qual o caso francês é exemplar: se a guerra franco-prussiana foi um dos meios para a Confederação do norte se unir aos estados do sul, a França não deixou, mesmo após a derrota na guerra, de ser um alvo de ataque permanente de Bismarck. Outrora Napoleão apostava na fragmentação alemã para não ter um estado potente como vizinho; agora é a Alemanha que investe no enfraquecimento da França por razões análogas, tendo por alvo o chauvinismo. Para tentar evitar o fortalecimento da França, Bismarck lança mão de uma estratégia original, qual seja, a de reforçar em solo francês a presença do catolicismo (um catolicismo que não deixaria de ser, evidentemente, "artificial". ${ }^{8}$ Com esse posicionamento, ele abandona literalmente a Kulturkampf — ao menos no plano de sua política externa. Como ele assevera: "Um estadista alemão sabe muito bem que a Igreja católica nunca terá os mesmos planos que a Rússia, e que se aliaria antes aos turcos do que a ela; sabe também que uma aliança entre Rússia e França ameaçaria a Alemanha". P Para além da estratégia geopolítica, Nietzsche entende que este obscurecimento do povo francês pode gerar uma reação contra a opressão religiosa, produzindo demanda por mais instrução. Noutros termos, o filósofo - expressando seu ponto de vista que parte exclusivamente de seus interesses - teme pela massificação cultura. ${ }^{\text {Io }}$

7 Podemos ver que, dada a Realpolitik do segundo Reich, que se aproxima da civilização (de traço francês) da qual com a guerra os alemães deveriam ter se distanciado ainda mais, Nietzsche se afasta da ideologia nacional-liberal. Estrategicamente, ele passa a aderir à ideia de cooperação e de unificação europeia. Outrora, as posições eram outras: dada a beligerância entre os alemães e os franceses, que era resultante, de certa forma, da sublevação antinapoleônica, desde a década de dez, e das Guerras de Libertação, a guerra franco-prussiana impóe-se natural e estrategicamente para os alemães, que visavam à unificação dos seus reinados, que seria facilitada com o acirramento do nacionalismo. Como estava crente que uma vitória alemã teria como resultado uma ação estatal que conduzisse o povo alemão para o encontro consigo mesmo, com sua alma, o filósofo, sem titubear, se aproximou do partido liberal-nacional, que pregava, dentre vários pontos, a unificação nacional.

8 Humano, demasiado Humano $₫$ 475, KSA 2.309-II, tradução de PCS.

9 Humano, demasiado Humano $₫ 453$, KSA 2.294-5, tradução de PCs.

IO Em outras palavras, atento à política de Bismarck, Nietzsche julga que o chanceler encon- 
No parágrafo intitulado "Religião e governo", de Humano, demasiado Humano, ele traz as razões desse seu temor. Entende que a religião é de extrema importância para o governo, na preservação "da paz civil interna" e para o "desenvolvimento contínuo" estatal, pois proporciona à "multidão" uma vida plenamente justificável, não tendo razões para se rebelar contra o Estado; ainda mais, a reverência religiosa se transfere para o Estado: "Assim, governo tutelar absoluto e cuidadosa preservação da religião caminham necessariamente juntos". ${ }^{.1}$ Os governantes são entendidos aqui como superiores justamente por saberem bem instrumentalizar a religião. De um lado, há aqueles cujo ofuscamento religioso não cabe (aos governantes); de outro, há aqueles que devem ser necessariamente ofuscados (a multidão). Se assim não for, o Estado corre risco. Nietzsche não deixa de pôr em evidência, nessa passagem, a seletividade de seu iluminismo.

Em suma, na mesma linha de uma primeira tradição liberal, que desconsiderava a democracia, Nietzsche considera que o esclarecimento à multidão não deve ocorrer. $\mathrm{O}$ grande risco aqui é portanto a democracia que bate à porta. Ao suprimir a distância entre os governantes e a multidão, fazendo que os superiores se vejam à serviço da vontade da multidão, os governantes passam a ter "a mesma atitude do povo ante a religiáo", isto é, passam a se submeter a um outro (no caso, à multidão). Dada a proximidade entre governantes e multidão, as luzes chegam a estes últimos, eliminando o ofuscamento religioso, fundamental para a manutenção do Estado. Daí ser imperativo para Nietzsche, já em Humano, demasiado Humano, combater a democracia. Daí igualmente - a seu ver - a inconsequência de Bismarck em sua interferência na França. É justamente nessa direção, que Nietzsche vê os incentivos ao regime republicano no Estado vizinho como maneira de proporcionar um enfraquecimento ainda maior na França. "É a mesma disposição de espírito que apoia o regime republicano no Estado vizinho - le désordre organisé, como diz Mérimée - pela razão única de supor que ele torna o povo mais fraco, mais dividido e menos apto para a guerra". ${ }^{12}$ Numa palavra, num caso como no outro, nota que a Realpolitik impera.

Se Bismark age em conformidade às suas conveniências, no que tange ao iluminismo (ao renegar parcialmente, por exemplo, a luta pela cultura $(\mathrm{Kul}-$ turkampf), podemos dizer que Nietzsche também se posiciona de maneira sui generis. Assim, as reticências do filósofo em relação à democracia têm por trás o vínculo que ele identificava haver entre as Luzes e a religião.

trou no chauvinismo a chave para alavancar economicamente a Alemanha. Ao suprimir da sua política externa a Kulturkampfe fomentar internamente o nacionalismo, entende que a Alemanha entra numa fase de obscurantismo.

II Humano, demasiado Humano $₫$ 472, KSA 2.302-7, tradução de PCS.

I2 Humano, demasiado Humano $\$ 453$, KSA 2.294-5, tradução de PCS. 
E aqui o iluminismo nietzschiano começa a ganhar nitidez. Atribuindo a Rousseau a responsabilidade, ou melhor, a superstição, que alimentou as revoluções (um verdadeiro fanatismo religioso), o filósofo preserva Voltaire, a seu ver, um pensador antípoda de Rousseau, podendo, dessa maneira, lançar mão das luzes para a crítica da religião e do nacionalismo dos nacional-liberais, de um lado, e do socialismo, de outro. Encontra em Voltaire apoio para um iluminismo parcial, que pode ser exemplificado na citação do pensador francês, de Humano, demasiado Humano: "quand la populace se mêle de raisonner, tout est perdu". Nessa direção, prossegue o filósofo alemão, afirmando que "é preciso adaptar-se às novas condiçõos, assim como nos adaptamos quando um terremoto muda as velhas fronteiras e os contornos do solo e altera o valor da propriedade".${ }^{13} \mathrm{O}$ perigo das Luzes é bem explicitada num outro parágrafo, agora de $O$ Andarilho e sua Sombra. Conforme afirma o filósofo: "Sua periculosidade se tornou, assim, quase maior do que a utilidade emancipadora e clarificadora que ele introduziu no grande movimento da revolução. Quem isto compreende, também saberá de qual mistura é preciso extraí-lo, de qual turvação é preciso filtrá-lo: para prosseguir a obra do Iluminismo em si mesma e sufocar no berço a revolução a posteriori, fazer com que não tenha sido" ${ }^{14}$ Distanciando de um iluminismo míope que resvala em atos de fé, como no caso de Rousseau, Nietzsche coloca-se na trilha de um iluminismo de caráter nitidamente conservador. Ele se mantém assim, como já havia se expressado em Sobre o Futuro de nossos Estabelecimentos de Ensino, contra o iluminismo para a massa. Age parcialmente ao enfatizar apenas alguns aspectos das Luzes na elaboração de seu novo quadro categorial, cujo objetivo último é o fortalecimento da Bildung.

Os traços do iluminismo nietzschiano ficam assim evidentes nesse momento de sua obra somente a partir da oposição entre Rousseau e Voltaire. Que Voltaire é, no entanto, um nome de destaque, ao lado de outros, Petrarca e Erasmo, não há dúvida. ${ }^{15}$ No conhecido aforismo em que Nietzsche esbraveja: "Ecrasez l'infâme'!" referindo-se ao "espírito otimista da revolução francesa", a fenda existente entre o iluminismo de cada um dos pensadores franceses se faz ver. No parágrafo "Uma ilusão na doutrina da subversão", Nietzsche critica a subversão

I3 Humano, demasiado Humano $₫ 438$, KSA 2.285-6. Não por acaso, Scarlett Marton, ao analisar o capítulo "A mulher e a criança", de Humano, demasiado Humano, afirma que, para além dos acentos iluministas, que o filósofo adota, há igualmente uma posição moralista: "ao se ocupar com a condição feminina, Nietzsche lança mão de procedimentos que em muito o aproximam dos moralistas franceses e, em particular de Pascal, mas quando trata das mulheres cultivadas as ideias que advoga são, em grande parte, tributárias da maneira de pensar de Voltaire" (Marton, 2014, p. 55).

I4 $O$ andarilho e sua Sombra $\$$ 22I. KSA 2.654. Tradução conforme Paulo César Souza (Nietzsche, 2008). A partir de agora, indicado como PCs.

I5 Humano, demasiado Humano $₫ 26$, KSA 2.46-8, tradução de PCs. 
ela mesma, que poderia ser "fonte de energia na humanidade". Em contraposição, coloca-se ao lado dos iluministas conservadores, que poderiam, por sua vez, contribuir para uma ação organizadora, "aperfeiçoadora da natureza humana" ${ }^{16}$ Verdadeiro espírito livre, pois conservador, e de posição aristocrática, Voltaire representaria "o espirito do Iluminismo e da progressiva evolução" afugentada pelo Iluminismo subversivo. ${ }^{17}$ Inspirando-se no combate de Voltaire às crenças religiosas, Nietzsche encontra os elementos de crítica necessários para combater as crenças nacionalistas encabeçadas pelos nacionais-liberais.

Para além das tentativas de interditar a educação para as massas, em nome de um iluminismo aristocrático, há duas outras ofensivas que precisam igualmente ser observadas, mesmo que sejam apenas citadas aqui. Primeira: o filosofar histórico, que, como assevera o filósofo, doravante se faz necessário, vem se opor à doença histórica, ao equívoco que atribui razão a todo processo histórico e, ainda mais, considera a modernidade o ápice desse processo. ${ }^{18}$ Segunda: o recurso à psicologia, que visa a combater os discursos de proveniência dos socialistas por justiça. Daí a análise dos sentimentos morais, que aparece num contexto bem preciso e com um alvo muito bem preciso. ${ }^{\text {I9 }}$

Isto posto, vê-se que Nietzsche deixa de aproximar, como fazia no período do Nascimento da Tragédia, a Alemanha da Grécia, para estabelecer um vínculo entre a Europa e a Grécia, ou seja, transfere para a Europa as expectativas que outrora focavam na Alemanha. Percebe-se também que o filósofo não acredita que a Europa terá o mesmo fim que a Grécia. Desfeita a aproximação com a Grécia, a Alemanha é vista como uma nova Roma, ou seja, como a encarnação da Realpolitk - e a unificação pode contribuir para reverte esse quadro. Nessa direção, acreditando que a Europa está a caminho da unidade, malgrado a existência de um forte ranço nacionalista ${ }^{20}$, Nietzsche mantém sua adesão às guerras de libertação, a que havia aderido aliás já no momento do Nascimento da Tragédia. Sabia que o expansionismo então em voga contribuiria positivamente para a causa nacionalista, que, a seu ver, deve ser rechaçada.

I6 Humano, demasiado Humano $\$ 463$, KSA 2.299, tradução de PCS.

I7 Humano, demasiado Humano $\$ 221$, KSA 2.I80-4, tradução de PCS.

I8 Cf. Humano, demasiado Humano $\$ 2$, KSA 2.24-5, tradução de PCS.

I9 Esse texto de Nietzsche corrobora a afirmação acima: "Seja qual for o resultado dos prós e dos contra: no presente estado de uma determinada ciência, o ressurgimento da observação moral se tornou necessário, e não pode ser poupada à humanidade a visão cruel da mesa de dissecação psicológica e de suas pinças e bisturis. Pois aí comanda a ciência que indaga a origem e a história dos chamados sentimentos morais, e que, ao progredir, tem de expor e resolver os emaranhados problemas sociológicos [grifo nosso]" (Humano, demasiado Humano $\$ 37$, KSA 2.59-6I, tradução de PCS).

20 Cf. Humano, demasiado Humano $\$$ 475, KSA 2.309-II, tradução de PCS. 
Pregando a unidade europeia para combater o chauvinismo, que era mantido na ordem do dia por Bismarck por meio da existência de uma falsa tensão entre a França e Alemanha (que visava a manutenção do estado-nação alemão), o filósofo vislumbra o surgimento de um homem europeu. Partidário do liberalismo econômico, aposta no movimento do capital para que as raças possam misturar-se:

O comércio e a indústria, a circulação de livros e cartas, a posse comum de toda a cultura superior, a rápida mudança de lar e de região, a atual vida nômade dos que não possuem terra — essas circunstâncias trazem necessariamente um enfraquecimento e por fim uma destruição das nações, ao menos das europeias: de modo que a partir delas, em consequência de contínuos cruzamentos, deve surgir uma raça mista, a do homem europeu. Hoje em dia o isolamento das nações trabalha contra esse objetivo, de modo consciente ou inconsciente, através da geração de hostilidades nacionais, mas a mistura avança lentamente, apesar dessas momentâneas correntes contrárias. ${ }^{21}$

Notemos que, além de manter como alvo a cultura, ele continua a atribuir um protagonismo à Alemanha. Se no período do Nascimento da Tragédia, Nietzsche assente que os alemães deveriam ser protagonistas na Europa, haja vista serem herdeiros do helenismo trágico, de uma civilização autêntica em contraposição a uma vulgar, não é outra a posição do filósofo a partir de Humano, demasiado Humano. Ele entende que cabem aos alemães o papel de serem os "intérpretes e mediadores dos povos". ${ }^{22}$ E por qual razão? Já no período da primeira Consideração Extemporânea não entendia a guerra franco-prussiana como sendo um embate entre civilizações, malgrado a diferença entre o espírito alemão e o neolatino. A vantagem alemã se dá pelo simples fato de considerar que a cultura alemã como não autóctone, mas como fruto da mistura de outras culturas. Dada a constituição do ser alemão — e não em virtude da superioridade cultural —, é intrínseca à alma alemã a tarefa de realizar a promoção da unidade dos povos. Se nos seus primeiros escritos considerava a Alemanha como herdeira do helenismo trágico, isso se dava à condição de não ser entendida como autóctone. Tal posição afirma-se, pode-se dizer, com o cosmopolitismo que caracteriza a Bildung.

Como vemos, o programa nietzschiano é o mesmo da juventude. São as mudanças factuais que exigiram uma nova perspectiva de apreensão da realidade e de ação. E, como decorrência, as mudanças nas posturas filosóficas, que não deram conta de seus objetivos, são radicalizadas. Podemos dizer também que Nietzsche passa posteriormente desse iluminismo aristocrático para um ultrailuminismo. Essa via iluminista na qual ele se coloca no período de Humano, demasiado Hu-

2I Humano, demasiado Humano $₫$ 475, KSA 2.309-II, tradução de PCS.

22 Ibid. 
mano não deixa de dar o tom às obras que se seguem: intensificando o recurso às teorias científicas da época, em particular às biológicas, psicológicas e físicas, torna a sua crítica à modernidade mais aguda ao desvendar no pormenor a procedência dos valores e cria uma interpretação de mundo que desvenda o funcionamento da realidade no seu conjunto. Conceitos como a doutrina da vontade de potência bem poderia aqui, se dissertássemos longamente a respeito, exemplificar essa nossa afirmaçãa.

No Gen temos uma escola de trabalho na filosofia de Nietzsche, que forma especialistas no trilho da melhor tradição filosófica nacional. Um dos pontos desse trabalho que gostaríamos de ressaltar gira em torno da revista Cadernos Nietzsche, fundada em 1996 por Scarlett Marton (http://www.scielo.br/scielo.

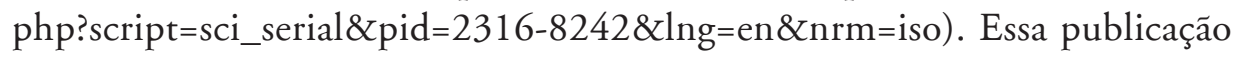
contribui para um repertório altamente qualificado no trabalho especializado no pensamento nietzschiano, trazendo ganhos inegáveis para quem se detém no capítulo "Nietzsche" na História da Filosofia. Proporciona ainda instrumentos para o trabalho de recepção da filosofia nietzschiana e, por conseguinte, para a compreensão de aspectos do pensamento brasileiro. Refiro-me aqui, nesse quesito, ao trabalho inaugural acerca da recepção de Nietzsche no Brasil, que é uma das frentes dos Cadernos Nietzsche. Enfim, a revista traz uma contribuição filosófica que se limitaria - no ver do filósofo - a um trabalho útil para algo mais elevado, digno dos ditos trabalhadores filosóficos, mas que, da perspectiva contemporânea, não deixa de ser um marco de excelência da nossa cultura especializada.

\section{Referências}

Itaparica, André. Nietzsche: estilo e moral. São Paulo, Ijuí. Discurso Editorial, Editora Unijuí, 2002.

Lebrun, G. O avesso da dialética. Hegel à luz de Nietzsche. Trad. Renato Janine Ribeiro. São Paulo: Cia da Letras, 1988.

Losurdo, D. O rebelde aristocrata. Trad. Jaime A. Clasen. Rio de Janeiro: Revan, 2009.

Marton, S. "Humano, demasiado Humano. Entre moralistas e iluministas". In: Nietzsche e a arte de decifrar enigmas. São Paulo: Loyola, 20I4, pp. 53-72.

MÉtayer, G. Nietzsche et Voltaire. Paris: Flammarion, 201 I.

NiETzsche, F. Sämtliche Werke. Kritische Studienausgabe (кsA), organizadas por Giorgio Colli e Mazzino Montinari. Berlim: Walter de Gruyter \& Co, 1967/1978. I5 vols. 
Nietzsche, F. Obras incompletas. Trad. Rubens Rodrigures Torres Filho. São Paulo: Nova Cultural, I989.

Nietzsche, F. Humano, demasiado Humano. Trad. Paulo César de Souza. São Paulo: Cia das Letras, 2000.

Silva Jr., I. Em busca de um lugar ao sol. Nietzsche e a cultura alemã. São Paulo, Ijuí: Editora da Unijuí, 2007.

SiLVA JR., I. "As posições políticas de Nietzsche em Humano, demasiado Humano: um pensador das Luzes?". In: Denat, C., Wothing, P. Humain, trop humain et les débuts de la réforme de la philosophie. Reims: Épure, 2017, pp. 38I-388.

Sternhell, Z. Les Anti-Lumières. Paris: Fayard, 2006. 